\title{
AACOM update
}

Deborah Heart and Lung,

202

Des Moines General

Hospital, 203

Douglas Laboratories, 181

Dura Pharmaceuticals

Ceclor CD, 189

Forest Laboratories

Esgic Plus, 226a, 226b

Janssen Pharmaceutica

Sporanox-Onychomycosis,

195-200

Knoll Pharmaceutical

Company

Vicoprofen, 185, 186

Pfizer Laboratories

Cardura, Cover 2, 177

Norvasc, 183

\section{G. D. Searle \& Company}

Covera, 179,180

Schering Corporation

Vancenase AQ, 193, 194

St. Francis Inc., 203

Zeneca Pharmaceuticals

Accolate, 215-218

Sular, Cover 3 , Cover 4

\section{Osteopathic medical school applicants optimistic about their future}

The students who entered colleges of osteopathic medicine (COMs) in the fall of 1996 were chosen from the largest pool of applicants ever-10,800. These applicants then submitted slightly more than five applications per person, for total applications in excess of 50,000. Many readers are aware that the American Association of Colleges of Osteopathic Medicine (AACOM) processes all applications for the COMs. In our initial projections, many of us at AACOM thought that the number of applicants for the entering class of 1997 would decrease. Our reasons for this assessment were as follows:

During the past 2 years, the number of new applicants has decreased, although the shortfall was compensated for by repeat applicants; and

Many newspaper articles and other media stories discussed the projected physician oversupply, and the fact that some physicians are unable to find employment in the specialty areas of their training.

Our projections, however, were incorrect. It now appears that the number of applicants for the fall 1997 entering class will parallel that of 1996. In an attempt to determine why the applicant pool remains high, we constructed a short survey sent to 1000 students who had applied through our application service. We have received 411 responses to date. A summary of the survey results includes: - Ninety-one percent felt that they would have no trouble finding a job upon completion of their training.

Eighty-four percent thought that because the population is getting older, there will be an even greater need for physicians.

Eighty-six percent stated that they were concerned with regard to the effect of managed care on their future career.

Eighty-eight percent thought that a career in medicine will afford them a comfortable financial status.

Only $16 \%$ of the respondents agreed that an oversupply of physicians exists; $64 \%$ of the respondents disagreed somewhat or strongly with the statement, "There is an oversupply of physicians."

A question relative to why applicants chose a career in medicine demonstrated that $73 \%$ of the respondents chose medicine because it provided an opportunity to help others.

Based on the results from this limited survey, we make these conclusions, which may or may not be generalized as follows:

Applicants either are not aware of or do not understand the potential effects of the impending physician oversupply.

They are realistic concerning the possible effects of managed care on their future practice.

- They hold sensible expectations concerning future earning potential.

We at AACOM think that it is our obligation as part of the osteopathic medical profession to make sure that our applicants are well informed concerning their potential future. Although plans are incomplete at this time as to the methods we will use to inform students, inserts in the application booklet and articles on the AACOM Internet home page are being considered.

\section{Douglas L. Wood, DO, PhD}

President

American Association of Colleges of Osteopathic Medicine

Chevy Chase, Md 